$\xi=1$

\title{
The level at which registered nurses utilise the nursing process in local-level primary health care practice in Namibia
}

\author{
Hermine Iita $^{1 *}$, Scholastika Iipinge ${ }^{2}$, Agnes Van Dyk ${ }^{2}$ \\ ${ }^{1}$ Lecturer for Community Health Nursing Faculty of Health Sciences School of Nursing Public Health Department \\ University of Namibia, Oshakati Campus \\ ${ }^{2}$ Professor of Nursing Science School of Nursing Public Health Department University of Namibia, Windhoek Campus \\ *Corresponding author E-mail: hiita@ unam.na
}

\begin{abstract}
The purpose of this study was to explore and describe the use of the Nursing Process by registered nurses in local level primary health care practice in Namibia. The findings were used to serve as a basis to develop strategies to support registered nurses in their daily local PHC practice. A quantitative research approach using a survey design with self-report questionnaire was used. The population consisted of two groups. The first group consisted of 239 registered nurses working in Clinics, health Centers and in Outreach Programs. The second group consisted of 39 registered nurses supervisors of the registered nurses in these facilities. Quantitative, descriptive analysis was used to summarize and organize data using tables and figures as well as t-test and analysis of variance (ANOVA), where applicable.

Five main problem areas were identified. It was concluded that strategies needed to be developed to support registered nurses in their daily local Primary health care practice. The development of strategies will be dealt with in a different paper.
\end{abstract}

Keywords: Local-Level Primary Health Care; Nursing Process; Primary Health Care; Registered Nurse; Strategies; Support.

\section{Introduction}

Primary health care (PHC) refers to essential health care and is based on practical, scientifically sound and socially acceptable methods and technology which are made universally accessible to individuals and families in the community and at a cost that the community and the country are able to afford and maintain at every stage of their development in the spirit of self-reliance and self-determination. (Monekoso 1994; WHO 2009).

The PHC philosophy was introduced and endorsed by 134 participating nations at an international conference on PHC, jointly sponsored by the World Health Organization (WHO) and the United Nations Children's Fund (UNICEF) and which was held at Alma Atta from 6 to 12 September 1978. Governments were urged to rationalise their highly technical approaches to health care delivery and to broaden their coverage by providing basic services. (WHO, 2009).

The basic essential elements of PHC are as follow: Water and sanitation; Health education ; Nutrition and food supply ; Control of endemic diseases ; Immunization; Supply of essential drugs ; Treatment of common diseases and injuries; Mother and child health care \& family planning .These elements of PHC, must be provided on the basis of the four principles, namely, equity, which seeks to ensure that all shall have equal access to basic health care and social services provided by the state; accessibility, which is the aim to extend health care services to all, with special attention being given to the disadvantaged regions of the country and to train community-based health workers so as to reach isolated small communities in rural areas; affordability, which states that PHC services should be provided free of charge to all citizens; and community involvement and participation, which advocates for the involvement of communities in health and social services pro- vided at their level, with the aim to make the communities masters of sustainable PHC (Stanhope \& Lancaster, 2008; Moseley, 2003). With the independence of Namibia in 1990, the Government of the Republic of Namibia adopted a health care system that places the focus on PHC, as a strategy to provide health care to all Namibians in order to make health services easily accessible and available to all communities in Namibia, at a cost that the country and the communities could afford and with the emphasis on community-based health care. (Government of the Republic of Namibia: MOHSS 1992).In addition, health workers including registered nurses were re-oriented as regard the implementation of this approach (Iipinge, 2000).

Accordingly, The University of Namibia revised the nursing education curriculum to prepare registered nurses to be ready to apply the PHC approach as adopted by the Government of Namibia (University of Namibia, 1995).

Apart from the MOHSS and the University of Namibia, the Government of Namibia encouraged communities to take ownership and to participate actively in matters affecting PHC delivery and to provide input into the health care delivery (GRNMOHSS, 1992; GRNMOHSS, 1995)

Nursing does not only involve the care of the sick and the dying, but its overall goal is to help people to accept responsibility for their own health as well as that of their families and communities, and to help them both to retain and to regain health.. Furthermore, the registered nurse should use the nursing process to render PHC. The nursing process is a systematic method of assessing data, coming to a conclusion (diagnosis), planning the activities of care accordingly, implementing these activities of care, evaluating the progress and recording everything that has been done (Jooste, 2010; Searle et al., 2009; ).

One research study conducted in Namibia regarding the use of the nursing process by registered nurses is the one by Van der Vyver 
(2007), titled: "Guidelines to implement an educational programme to internalise and operationalise the nursing process in the gynaecology wards of the training hospitals of Namibia". This was a qualitative study done with the purpose of exploring and describing the operationalisation of the nursing process among registered nurses who work in the gynaecology wards of Namibian training hospitals. The aim of the research was to develop a programme that would facilitate the utilisation of the nursing process, as well as to develop guidelines for its implementation.

The finding of this study indicated that not all registered nurses in the gynaecology wards used the nursing process, a situation which could contribute to defective nursing care in this area. The study recommends that registered nurses need support so that they will use the nursing process effectively and be able to care for patients holistically in their daily practice. The study further mentioned that many court cases laid by patients against nurses in Namibia could be prevented by the use of the nursing process because, through it, nurses have an opportunity to identify patients' problems systematically and to come up with the correct care plan to implement in each case.

In this study the nursing process is described as a logical and rational method of problem solving that enables registered nurses to make intelligent decisions about patient care, instead of relying on an unsystematic and intuitive process. Although the nursing process is regarded by many nurses as time consuming, it is the only systematic way of problem solving as it is the process of identifying nursing problems and interpreting, analysing and selecting appropriate courses of action to solve these problems. It is a tool that nurses use to think critically about the nursing care they render.

The nursing process has its roots in systems theory and the steps of the nursing process facilitate holistic problem solving. These steps are presented as follows: Assessment is the first step and involves the process used by nurses to draw conclusions about patients' strengths and health concerns. Assessment, thus, ends up in the second step, diagnosis, which is about specifying health concerns and strengths. Planning is the third step and entails the development of approaches to meet patients' needs. After planning, comes the fourth step, implementation, which comprises the actual care provided by the nurse. This involves completing specific activities to help the patient meet the goals in the plan while continuing to think about what is being done, how it is being done, and when, where, and why it is being done. The fifth step following implementation is evaluation. This is a determination of the patient outcomes and the quality of care. It involves thinking and collecting information about the patient's response after nursing care has been provided and working on determining whether the patient's goals and objectives have been attained and how well they have been attained. The last step is documentation, which is about recording the nursing actions that have been performed so that the quality of care is not affected. Furthermore, the nursing process is a problem-solving framework that enables the nurse to plan care for a client on an individual basis.

In applying the nursing process during their daily practices when rendering PHC services, registered nurses have roles and functions to perform namely, the instrumental and the expressive roles. The instrumental role is concerned primarily with the acquisition of knowledge about the health situation and the evaluation of such knowledge in the search for a possible solution to the problem. On the other hand, the expressive role involves the establishment and maintenance of an extensive and effective therapeutic environment, as well as assisting the patient/client to become receptive to therapeutic intervention. This, in turn, implies that nurses should accept the patient/client as he/she is, support him/her through his/her problem or needs and identify the health needs of patients correctly when rendering PHC services. This role requires that a registered nurse treat all patients/clients humanely, including those patients/clients with mental distress/illnesses (Barnald \&Locsin, 2007; Searle et al., 2009).

There are several functions involved in the various roles played by nurses. These functions refer to those key activities for which the registered nurse, as an accountable person, takes responsibility realising the objectives of knowledgeable, competent and legally and ethically based patient care. The functions of the registered nurse may be placed into three categories, namely, dependent, interdependent and independent functions. The dependent functions relate to the law that authorises the nurse's practice, while one aspect of the independent function relates to all the factors inherent in the assessment, diagnosis, planning, implementation and recording of patients/individuals, families and communities. On the other hand, the interdependent function relates to the interrelationship between the nurse and various members of the health team as regards those activities which are required by patients, clients and communities (Searle et al., 2009).

It is expected that registered nurses in Primary health care utilise the nursing process when they execute their daily functions. However, it is not clear whether registered nurses utilise the nursing process effectively in the provision of PHC, as adopted by the government, as a new and better strategy to render health care services in the country after independence in 1992.

This question was raised because health care statistics do not always reflect whether PHC is being executed satisfactorily. Research findings reveal insufficient health communication with clients in health care facilities (Iiyambo, 2005; Neshuku, 2005; (GRN MOHSS, 2006), while an increased prevalence of HIV/AIDS and tuberculosis and a lack of a healthy lifestyle are being observed in society.

It is as a result of these problems that the researchers in this study explored and described the extent to which registered nurses utilise the nursing process with regard to the delivery of PHC during their daily practice and, subsequently, developed strategies that would support registered nurses in their utilisation of the nursing process when executing their roles and functions in this regard.

This study was conducted in terms of both the framework of the model of nursing process, as well as the elements of PHC as applied to the role and functions of registered nurses and their supervisors in the PHC facility practice setting.

\section{Aim and objectives of the study}

The purpose of this study is twofold: firstly, to explore and describe the extent to which professional nurses use the nursing process in the delivery of PHC in their daily practice and, secondly, to develop strategies that would support registered nurses in their utilisation of the nursing process when executing their roles and functions in this regard.

The following research objectives were as follow:

To explore and describe the way in which registered nurses in clinics, healthcare centres and outreach posts in the health districts use the nursing process in PHC delivery

To determine how supervisors perceive the utilisation of the nursing process by registered nurses in $\mathrm{PHC}$

To identify the constraints that registered nurses are faced with when utilising the nursing process in the delivery of PHC

To develop a conceptual framework on which to base the formulation of relevant strategies

To incorporate the findings of this study into the development of strategies to support registered nurses in their utilisation of the nursing process in PHC delivery

To validate the effectiveness of these strategies

\section{Study design and methods}

The study was conducted in four phases namely as follow: Phase1: Needs assessment quantitative survey; Phase 2: Conceptualisation of findings from phase 1; Phase 3: Development of strategies to support the roles and functions of the registered nurse in local level PHC and Phase 4: Validation of these strategies.

This article describes objectives 1 and 2 namely, 1).To explore and describe the way in which registered nurses in clinics, healthcare centres and outreach posts in the health districts use the 
nursing process in PHC delivery and 2). To determine how supervisors perceive the utilisation of the nursing process by registered nurses in PHC. These two objectives made up the major part of phase 1 of this study, which is a needs assessment.

\subsection{Design}

A quantitative research approach using a survey design with selfreport questionnaire was used. The data that were gathered were on the application of PHC role functions during practice by registered nurses. This study was conducted in state clinics, health centres and outreach posts in health districts in all the health regions of Namibia.

The population comprised two groups. The first group consisted of 236 registered nurses working in clinics, health centres and outreach posts. The second group comprised 39 registered nurse supervisors, who supervised the registered nurses in these facilities. As a result of the restricted number of participants (registered nurses), the population and the sample were the same for this study and there was no sample selection.

The comments of the nursing service managers were scrutinised and used to inform the questionnaire. Two questionnaires were developed, one for registered nurses and the other for supervisors. The content of these two questionnaires was the same.

The questionnaires consisted of both open- and closed-ended questions and contained the following sections:

Section A consisted of biographical information -respondent's age, duration of service as a registered nurse, gender, work area, nursing qualification, duration of service at the current health facility, health district and health region.

Sections B to G consisted of items concerning the implementation of the PHC role functions within the study framework of the nursing process.

Section B dealt with assessment; section C diagnosis; section D planning; section $\mathrm{E}$ implementation; section $\mathrm{F}$ evaluation and section $\mathrm{G}$ recordkeeping.

This questionnaire was designed in such a way as to yield information on the entire targeted role functions that a registered nurse in local-level PHC in Namibia is expected to fulfil. Validity, reliability and pretesting

Validity and reliability was ensured by: submitting the instrument to her supervisors and also by means of a peer reviews. The supervisors agreed that the items that appeared were representative of the purpose of the study; content validity was assured by making sure that the questionnaire adequately covered the topic under study, namely, the utilisation of the nursing process in local-level PHC practice by registered nurses in their daily practice; In this study, the questionnaires were pretested to ascertain that the wording of the questions was not ambiguous. The questionnaires were also distributed to the senior nurse managers at the MOHSS in Namibia for review as recommended in literature (De Vos et al., 2011; Jooste, 2009).

The questionnaires were either posted or delivered by hand to the participants, and then returned by post or collected by the researcher. The respondents - supervisors and registered nurses were requested to complete the questionnaires. One supervisor could fill in more than one questionnaire if she/he supervised more than one registered nurse. Table 1 below summarises the statistics on questionnaires sent out and returned.

Table 1: Statistics of the Questionnaires Sent Out and Returned

\begin{tabular}{llll}
\hline & Sent out & Returned & Percentage \\
\hline Registered nurses & 236 & 164 & 69.4 \\
Supervisors & 236 & 144 & 61.0 \\
Total & 472 & 308 & 65.2 \\
\hline
\end{tabular}

Quantitative data analysis was done and involved the coding, categorising, ordering and systematic organising of the data in order to provide meaningful results (Levine \& Stephan, 2010). Descriptive analysis techniques were used to summarise and organise the data, using tables and figures to present the summarised findings.
In addition, a t-test and analysis of variance (ANOVA) were performed on the data, where applicable. Post hoc tests that were utilised included Scheffe/Dunnett, Tukey and LSD. The aim of using the post hoc tests is to verify whether the differences suggested by ANOVA are statistically significant and also to point out exactly where the differences lie among the groups (Ott \& Longnecker, 2010).

Data analysis: The descriptive data arising from the items on the questionnaires, where the registered nurses and their supervisors rated the fulfilment of the various PHC role functions by registered nurses, were analysed in order to determine the level at which each item had been rated. The mean score for each item were determined and this served as a yardstick for classifying specific items as well done, required moderate action or required urgent action. All the findings were presented in a comparison format in terms of which the ratings by the registered nurses were compared to the ratings by the supervisors. Student's t-test and ANOVA were also performed on specific variables to determine significant differences and their related variables.

After the data analysis had been completed, the researcher identified those functions which had been well done and for which the performance needed to be sustained, the functions which had required moderate actions and the functions that had required urgent actions. An item was classified as needed urgent action if rated by more than $20 \%$ of the responses as below average.

Three patterns were expected, namely, performance to be sustained (to sustain performance: $90 \%$ and more rated at average and higher); performance in terms of which moderate action is required (moderate action required: $80-89 \%$ rated as average and higher) and performance in terms of which urgent action is required (urgent action necessary: $>20 \%$ rated below average). These patterns are represented in figure 1.

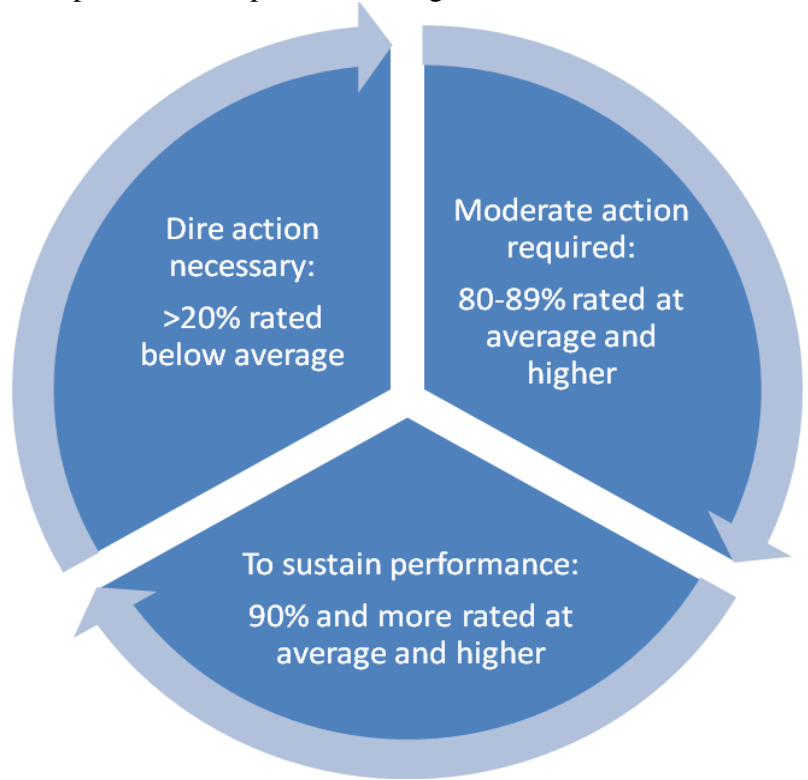

Fig. 1: Categorisation of Role Functions Based on the Rating of Their Fulfilment by the Participants

With data analysis, a summary of the findings is presented in accordance with these patterns, namely, performance to be sustained, moderate action required and urgent action necessary.

The reader is advised to refer back to this section should the need arises.

Ethical measures were observed as follow: Written permission to conduct this study was granted by the MOHSS in Namibia before the data collection in phase 1 of the study commenced. Participants were fully informed regarding what the study entails. Confidentiality in this study was ensured because; the raw data were not shared in any way that may have jeopardised the safety of the participants. Participants in this study were told that they could refuse to participate in the study or could withdraw from the study 
at any time without any fear of coercion, thus voluntarism was ensured.

The anonymity of all the participants in this study was ensured in this way that the data from the field were not in any way linked to the individual respondent, while only data that was necessary for the project were collected. On completion of the study a copy of the complete study report was given to the Ministry of Health and the University of Namibia.

The participants in this study were not, in any way, exposed to either physical tests or treatment (Ervin, 2002).

\section{Findings}

\subsection{The demographic presentation of the participants}

In terms of age, a large number of the registered nurses fell in the age group of 45 years and above, followed by those registered nurses aged 35 to 44 , with a few only of the participants being under 35 years of age. This finding indicates that the majority of the participants were in middle to late adulthood and, thus, that more stable personalities were supporting the service provision requirements for PHC. This finding further suggests the availability of mature supervisors who would be able to manage the execution of the elements of PHC elements in practice (Heneman III \& Judge, 2009).

The majority of the participants ( $87 \%$ or 268 out of 308 ) had been in the nursing profession for a period of at least four years, while the supervisors had relatively more years of experience of service as compared to the other registered nurses. The latter finding indicates experienced supervisors who would be able to cope as a result of their prolonged exposure to the work situation, although it may also imply the possibility of resistance to change (Heneman III \& Judge, 2009).

As far as gender was concerned, $19.8 \%(\mathrm{~N}=61)$ of the participants were male and $80.2 \%(\mathrm{~N}=247)$ female - a female to male ratio of approximately $4: 1$. This finding is in line with the findings of the WHO (2009), namely, that it is women who are mainly engaged in community-oriented health care services.

The majority of the participants were working in clinics as compared to those who lwere working in health centres, mobile teams or outreach health posts. This is in line with staffing and health facility structures.

Of the research participants, 5\% (46 out of 306) only, and mainly the supervisors, had a bachelor's degree or above, while the remainder of the respondents (260 out of 306) had a diploma. Until 2007 , the only way in which to obtain a nursing qualification in Namibia was by means of a university diploma with a bachelor's degree as a post basic qualification with one major subject in Community Health Nursing and a second major subject in either Health Service Management or Nursing Education.

\subsection{Findings on the fulfilment of the primary health care role functions in the context of the nursing process}

A total of 67 role functions were rated. In order to ensure that the data were meaningful, all the descriptive statistical tables (assessment to recordkeeping/documentation) were presented in such a way that they are grouped together. This grouping together of the data allows for patterns to emerge and increased focus on problem areas.

In addition, all the descriptive statistics tables were presented in a comparative format with a comparison always being made between the responses of the group of registered nurses and the responses of the supervisors. As an example, table 2 has been included to demonstrate how the data is summarised. As an example, in table 2, which presents the descriptive statistics pertaining to the assessment step, item number 1, which involves an assessment of the occurrence of health problems in the catchment area, was rated below average by $13.5 \%$ of the registered nurses and by $12.7 \%$ of the supervisors. However, the same item was rated as average by $31.9 \%$ of the registered nurses and by $33.1 \%$ of the supervisors, while $54.6 \%$ of the registered nurses responses and $54.2 \%$ of the supervisors' responses rated the same item as above average. In the table, the total number of responses in each case is in brackets, just below the relevant percentage.

The last two columns on the extreme right-hand side of the table indicate the mean rating of the fulfilment of each function by the registered nurses (3.65) and by the supervisors (3.54) and, lastly, the mean rating of the fulfilment of each specific item according to the combined, total responses of the registered nurses and the supervisors together (3.60).

\subsubsection{Overview of the overall fulfilment of the $\mathrm{PHC}$ role func- tions based on the phases of the nursing process}

The information regarding the steps of the nursing process demonstrates that the mean fulfilment of the PHC role functions ranged between 2.93 and 4.70 .

The mean fulfilment of the functions according to the steps of the nursing process, which reflected the average view of performance for the all items pertaining to each step of the nursing process, is presented in figure 2. The means are displayed in the middle of each bar.

4.2.2. The assessment step as a prerequisite for the implementation of the elements of primary health care

The assessment phase concentrated on 19 role functions as presented in table 2 .

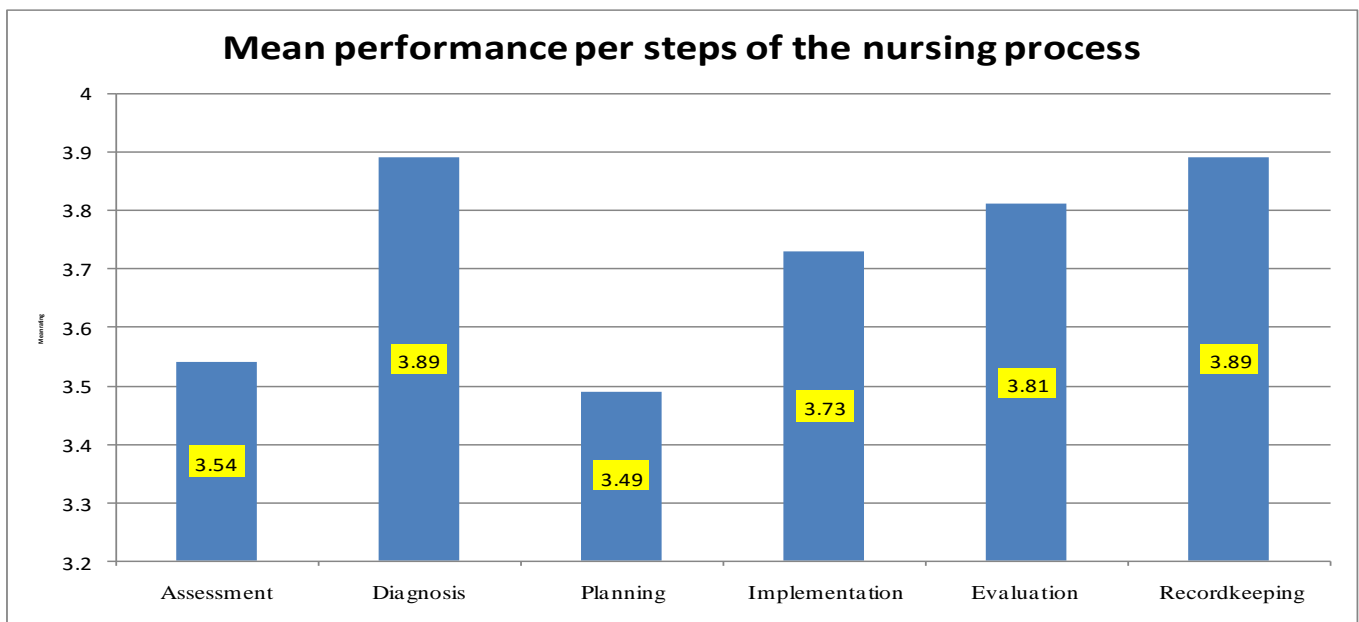

Fig. 2: Mean Fulfilment of Role Functions by Registered Nurses According to the Steps of the Nursing Process. The Means are displayed in the Middle of Bars. [Note: The Possible Highest Score Is 5 and the Lowest Possible Score Is 1] 
The assessment step/phase of the nursing process is the first component that will be presented and discussed.

Table 2: Statistical Results of the Assessment Step: Percentages (\%), Means and Frequencies (N)

\begin{tabular}{|c|c|c|c|c|c|c|c|c|c|}
\hline & \multicolumn{2}{|c|}{$\begin{array}{l}\text { PERCENTAGES } \\
\text { below average }\end{array}$} & \multicolumn{2}{|l|}{ average } & \multicolumn{2}{|c|}{ above average } & \multicolumn{3}{|c|}{ MEAN } \\
\hline & $\mathrm{R} / \mathrm{n}$ & Sup & $\mathrm{R} / \mathrm{n}$ & Sup & $\mathrm{R} / \mathrm{n}$ & Sup & $\mathrm{R} / \mathrm{n}$ & Sup & Total \\
\hline $\begin{array}{l}\text { Occurrence of health prob- } \\
\text { lems in your catchment area. }\end{array}$ & $\begin{array}{l}13.5 \\
(\mathrm{~N}=22)\end{array}$ & $\begin{array}{l}12.7 \\
(\mathrm{~N}=18)\end{array}$ & $\begin{array}{l}31.9 \\
(\mathrm{~N}=52)\end{array}$ & $\begin{array}{l}33.1 \\
(\mathrm{~N}=47)\end{array}$ & $\begin{array}{l}54.6 \\
(\mathrm{~N}=89)\end{array}$ & $\begin{array}{l}54.2 \\
(\mathrm{~N}=77)\end{array}$ & 3.65 & 3.54 & 3.60 \\
\hline $\begin{array}{l}\text { Occurrence of important } \\
\text { diseases in the community }\end{array}$ & $\begin{array}{l}16.2 \\
(\mathrm{~N}=26)\end{array}$ & $\begin{array}{l}9.2 \\
(\mathrm{~N}=13)\end{array}$ & $\begin{array}{l}30.4 \\
(\mathrm{~N}=49)\end{array}$ & $\begin{array}{l}35.5 \\
(\mathrm{~N}=50)\end{array}$ & $\begin{array}{l}53.4 \\
(\mathrm{~N}=86)\end{array}$ & $\begin{array}{l}55.3 \\
(\mathrm{~N}=78)\end{array}$ & 3.6 & 3.6 & 3.60 \\
\hline $\begin{array}{l}\text { Safety of drinking water for } \\
\text { clients in catchment area }\end{array}$ & $\begin{array}{l}24.0 \\
(\mathrm{~N}=31)\end{array}$ & $\begin{array}{l}21.9 \\
(\mathrm{~N}=31)\end{array}$ & $\begin{array}{l}24.8 \\
(\mathrm{~N}=54)\end{array}$ & $\begin{array}{l}38.0 \\
(\mathrm{~N}=54)\end{array}$ & $\begin{array}{l}50.3 \\
(\mathrm{~N}=81)\end{array}$ & $\begin{array}{l}38.0 \\
(\mathrm{~N}=54)\end{array}$ & 3.29 & 3.28 & 3.31 \\
\hline
\end{tabular}

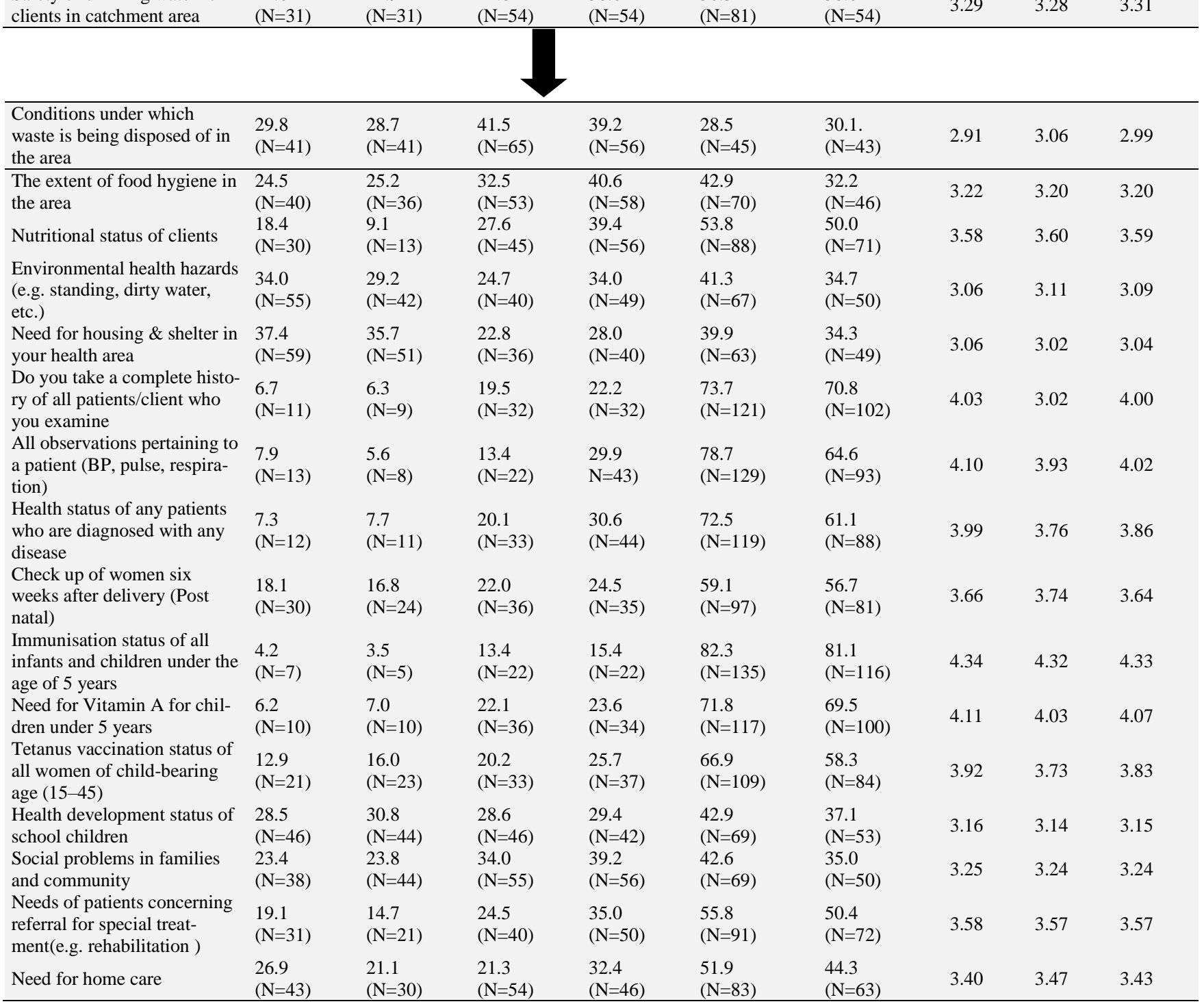

In accordance with the explanation given above regarding the way in which the data are presented, table 2 demonstrates that, of these 19 assessment role functions those that are categorised as well done (performance to be sustained) include history taking, baseline observations executed, health status assessment, immunisation status of infants and children under five years of age, and assessment for the need for Vitamin A by children under five years of age.

Those assessment functions that were categorised as requiring moderate actions included the assessments of the following: occurrence of health problems in the catchment area; occurrence of important diseases in the community; tetanus vaccinations for all women of childbearing age (15-49), check-up of women at six weeks after delivery, need for referral for special treatment, and the nutritional status of clients.

The following assessment functions were categorised as needed urgent actions namely; the assessment of the safety of drinking water for clients, conditions under which waste was being disposed of, the extent of food hygiene, environmental health haz- ards, for example, standing, dirty water, need for housing and shelter in the health area, health developmental status of school children, social problems in families and communities, and the need for home care.

As far as the ANOVA results and association with the demographic variables were concerned, no statistically significant differences were found as regard any of the demographic variable and the assessment functions performed by registered nurses in local-level PHC facilities.

\subsubsection{Diagnosis as a prerequisite for the implementation of the elements of primary health care}

The diagnosis step focused on ten functions. These findings indicate that, of these ten diagnosis role functions, five categorised as well done; five were categorised as needing moderate actions while none was categorised as needing urgent action.

The five diagnosis role functions that were categorised as well done included the following: determination of the catchment population; determination of immunisation status; identification of 
disease trends reflected in health information system records; identification of resources needed in the provision of nursing care and making a correct nursing diagnosis of all patients or clients. Those diagnosis role functions that were categorised as needing moderate actions included the following: knowledge of the size of the catchment area; identification of the socioeconomic situation of the community; identification of training needs of the community; identification of the training needs of health workers, including nurses, and carrying out a full physical examination of all clients.

A statistically significant difference was found regarding the length of time for which a registered nurse had worked at a health facility, and the performance of nursing diagnoses $[\mathrm{P}=0.038$ (overall) and for Group 1 ( 3 years or less) as compared to Group 2 (4-10 years), where the $\mathrm{P}$ value was 0.044 according to the Tukey HSD Test]. Thus, the implication is that the longer the length of service in a specific health facility, the more comprehensive the nursing diagnoses.

\subsubsection{Planning as a prerequisite for the implementation of the elements of primary health care}

In this study the planning phase of the nursing process focused on eleven (11) functions.

Of these 11 planning role functions, not one was categorised as well done, six were categorised as needing moderate action, while five were categorised as needing urgent action. Lippincott and Wilkins (2006) and Viljoen and Sibiya (2009) warn that, if proper planning is not carried out, there is a greater possibility that the interventions will be unsuccessful.

The six planning role functions that were categorised as needing moderate actions include the following: planning for the delivery of nursing care based on the catchment population of the community; the planning of services based on the health information system data available at a specific health facility (morbidity and mortality); the development of a teaching plans for individuals designed to promote health; the planning of training sessions for staff on relevant issues; planning for health promotion activities (e.g. growth monitoring, home visiting, AIDS prevention, immunisation) and the planning of nursing interventions for health related problems which have been identified.

The planning functions which were categorised as needing urgent actions include the following: planning programmes to manage illnesses of an acute and/or chronic nature; contribution to planning annual budgets to request resources (manpower, materials); contributions to the planning of a project proposal to request resources according to needs; planning of training sessions for the community concerning health issues and the planning of outreach services in the community.

In addition, a statistically significant difference was found in relation to the area of practice and how well the planning phase had been completed [P $=0.047]$. Thus, the implication is that registered nurses who work in health centres are not involved in outreach services to the same extent as are those who work in clinics and outreach posts.

\subsubsection{Implementation of the elements of primary health care}

The implementation functions that were categorised as well done included the following: The completion of planned nursing intervention activities for the catchment population; the management of any health problem within the framework of the scope of practice; the provision of health education according to the health needs of the clients; the administering of treatment and medications as authorised by both the Nursing Act and relevant regulations and safeguarding the rights of individual patients. Those implementation functions that were categorised as needed moderate actions included the following: Utilisation of the available resources in the community when carrying out nursing intervention roles and functions; referral of clients to the health services available in the community; involving family members when fulfilling nursing roles and functions; carrying out roles and func- tions related to the control of outbreaks of disease and disasters and ensuring that resources provided for nursing projects are utilised for the correct purpose.

The four implementation functions that were categorised as needing urgent actions include: conducting training sessions for all health workers and the community; implementing the budget requirements as planned; providing home care according to the needs of clients and carrying out research on problems which have been identified.

Some of the registered nurses indicated that the involvement of family members in the care of the patients was not applicable to their area of work, although the literature recommends that this is the major function of the PHC practitioner.

The statistical analysis performed regarding the implementation step of the nursing process identified two statistically significant differences associated with gender and area of practice/work [Gender: $\mathrm{P}=0.018$, t-test and area of practice: $\mathrm{P}=0.012$ ]. Thus, the implications are that, in terms of gender, being male was associated with a higher level of implementation as compared to being female as regards the fulfilment of PHC roles and functions, while working in outreach was associated with a higher level of implementation of the PHC elements as compared to working in health centres, clinics and health posts.

However, explanations of the reasons for these findings are beyond the scope of this study, although further research may provide such explanations.

\subsubsection{Evaluation as part of the implementation of the elements of primary health care}

In this study the focus during the evaluation phase of the nursing process was on five role functions of the registered nurse in PHC. The data demonstrate that, of the five role functions listed under evaluation, two were categorised as well done; three were categorised as needed moderate actions, while none was categorised as needed urgent actions.

The two evaluation functions that were categorised as well had done are: evaluation of the ways in which materials and supplies are used for nursing care and evaluation of the effectiveness of health programmes, for example, immunisation.

The three evaluation functions that were categorised as needed moderate actions included the monitoring of changes in the occurrence and presence of health problems; evaluation of the effectiveness of health education programmes and evaluation of the health progress of all categories of patients/clients. As with previous studies on health education and support in PHC that had captured similar information regarding health education, the results of this study demonstrate that the commitment of nurses in PHC facilities to health education and health education programme approaches needs to be strengthened (Iiyambo, 2005; Neshuku, 2005).

In addition, the statistical analysis performed regarding the evaluation step of the nursing process did not pick up any significant differences in the fulfilment of the PHC role functions.

\subsubsection{Documentation of activities related to the implementa- tion of the elements of primary health care}

In this study the documentation step of the nursing process focused on eight functions. The documentation role functions that were categorised as well done include the following: ensuring the correctness of the health information available at health facilities; documentation of all the nursing care activities provided and documentation of all the health information required for the Health Information System (HIS). The implication is that a correct HIS will contribute to the proper planning of health services while good recordkeeping serves as an effective communication tool among health care providers and as a research tool as well as legal evidence (Walliman, 2006; Wilkinson, 2007).

Five recordkeeping role functions were categorised as needing moderate actions and they are: Ensuring that the written health profile documents pertaining to the health area and kept at the 
health facility are up to date; documentation of incidences of health problems and important diseases in the community; documentation of all training sessions conducted for both the community and staff; documentation of all health promotion activities conducted and communication of findings with stakeholders (written and spoken). None of the recordkeeping role functions was categorised as needing urgent actions.

\subsection{Summary of the findings on individual elements of primary health care}

(PHC), aspects of community diagnosis and care and the management support or administrative functions

Section 4.2 above presented the findings pertaining to the fulfilment of the PHC role functions according to the steps of the nursing process. However, in order to obtain a clearer understanding of the way in which the fulfilment of these role functions by registered nurses was viewed by the participants in relation to the individual elements of PHC, this section contains a summary in this regard. The findings in that regard context are as follow:

\subsubsection{Health education and communication}

No function under this element of PHC was categorised as well done. Despite the fact that the training needs of the community had been identified the planning of community training sessions required urgent action. In addition, where patient training had been conducted, the family members had been only moderately involved. The functions that required urgent action included the following: Developmental status of school children not adequately assessed; patient education not sufficiently planned for; need for home care not sufficiently assessed; outreach services not sufficiently planned for; home care not adequately provided and education of other health workers not adequate.

\subsubsection{Nutrition and food supply}

None of the role functions in this respect were categorised as well done. Food hygiene had not been sufficiently assessed while the assessment of the nutritional status of any client had been only moderately done

\subsubsection{Control of endemic diseases}

The functions related to the control of endemic disease outbreaks and disasters were moderately fulfilled. However, coupled with the poor assessment of environmental sanitation and in view of cross-border interactions, this implies that the risk of incidences of communicable diseases remains (Minaar, 2008; Fraser \& Cooper, 2009)

\subsubsection{Immunisation against major preventable diseases}

The tetanus vaccination status assessment of all women of childbearing age (15-49) and the identification of immunisation coverage (EPI) in the catchment area were well done. The data also indicate that the registered nurses in the PHC services were identifying the immunisation status (EPI) coverage attained in the catchment area, with this knowledge enabling them to decide on what action to take in order to ensure an acceptable level of coverage of EPI vaccination antigens ( Kortenbout et al., 2009).

\subsubsection{Supply of essential drugs}

Medication and other treatment were being administered as authorised by both the Nursing Act, 2004 (Act No. 8 of 2004) and the relevant regulations. The registered nurse administers those treatments prescribed by either him/herself, as well as those prescribed by other health care service providers such as medical doctors and dentists. In addition, the registered nurses uphold patients' rights.

\subsubsection{Treatment of common diseases and injuries}

The following role functions of the PHC elements concerned with treatment of common diseases and injuries were well done: assessment of comprehensiveness of history taking of patients who are examined; assessment of all observations carried out in respect of patient such as blood pressure, pulse, respiration; assessment/checking of the health status of any patient diagnosed with any disease; identification of resources needed in the provision of nursing care; making correct nursing diagnoses; provision of health education according to the needs of clients/patients; safeguarding the rights of individual patients when executing the nursing role functions of PHC and the recording of the nursing role functions that have been executed.

These findings imply that health problems will be identified correctly and, thus, the correct treatment of clients or, in other words, the correct implementation of care plans (Viljoen \& Sibiya, 2009). Observing the rules and regulations for practice, including those set by the nursing regulatory body in the country, enhances the safety of patients under the care of registered nurses. In addition, the fact that health education is provided according to the needs identified provides an opportunity for individualised patient care. Those functions that required moderate actions include the following: assessment of needs of patients as regards referral to special treatment (e.g. rehabilitation); planning of daily nursing care according to the needs of the target catchment population; carrying out of physical examinations on patients; utilisation of available resources in the community when carrying out nursing (intervention) role functions; referring clients to the health services available in the community and the evaluation of the progress in the health of all categories of patients/clients.

If clients are not referred as early as possible or if their condition is not reported at all, this may result in severely complicated health problems (Lippincott Williams and Wilkins, 2006).

In conclusion, the results indicate that registered nurses provide adequate care in cases of disease conditions and in the provision of essential physical health care services. However, the assessment of the house/home and environment where the patients live would benefit from greater attention.

\subsubsection{Mother and child health care services, including family planning}

The assessment of the immunisation status of all infants and children under the age of five years and also assessment of the need for Vitamin A in children under the age of five years were well done. However, the assessment of women six weeks after delivery (postnatal) was only moderately done.

\subsubsection{Water and sanitation and other environmental health issues}

All the role functions to do with water and environmental sanitation carried out by registered nurses in local-level PHC needed urgent action: the safety of drinking water for patients, the manner in which waste was disposed of in the catchment area, the presence of environmental health hazards in the catchment area and the housing needs/environment of the patients/clients were all inadequately assessed by the registered nurses.

\subsubsection{Community diagnosis and community care}

The following functions under this component were well done: the catchment population that was being served, including specific age groups, was satisfactorily determined/diagnosed; all the planned nursing intervention activities for the catchment population (e.g. health promotion, home visits and immunisation were satisfactorily carried out, although it was mentioned that these were not sufficiently planned for, however, when they were planned for they were carried out; health problems were well managed within the framework of the scope of practice of the 
registered nurses and the disease trends reflected in the HIS were satisfactorily identified.

Taking note of the HIS data in order to discern disease trends is a good sign, as this reflects the fact that registered nurses understand that they must be vigilant about incidences of the various diseases and their trends, including unusual diseases which need to be detected as early as possible. An unusual disease refers to those diseases that are not usually expected in the country concerned and include diseases such as cholera, polio and others.

The following functions were moderately done: assessment of the occurrence of health problems in the catchment area; assessment of the occurrence of important diseases in the community; knowledge of the size of the catchment population; identification of the socioeconomic situation in the community; planning of interventions for any health problem identified; planning of health promotion activities such as growth monitoring, home visiting, AIDS prevention, immunisation; and changes in the occurrence and presence of health problems. In addition, all the health promotion activities conducted were moderately documented while incidences of health problems and important diseases in the catchment area/community were moderately recorded. However, some of the respondents indicated that knowing the size of the catchment population and identifying socioeconomic conditions were not applicable to their area of work.

Knowledge about the various socioeconomic situations places the registered nurse in a better position to plan the appropriate nursing care services for the specific community (GRN MOHSS, March 2006), while failure to document and to report means that other health care providers are deprived of information about the health situation. In some instances, this failure may mean that the health conditions develop into major health problems before they are contained (Stanhope \& Lancaster, 2006).

Under this component, the assessment of the social problems of families and communities was not sufficiently done. In her study on the implementation of the sociology of development by registered nurses, Shikongo (2008) found a similar situation, specifically to do with the assessment of abuse.

\subsubsection{Management and support or administrative functions}

The following functions were well done: ways in which materials and supplies had been used for nursing care were well evaluated; the effectiveness of health programmes, for example immunisation was well evaluated, accuracy of HIS at health facilities was ensured (documented); and all the health information needed for the HIS was well documented.

A cost effective health care service involves little or no waste of resources. This may involve the use of high technology resources for minor ailments that could be dealt with in a different manner. Further examples include polypharmacology, injections and antibiotics; cough remedies; use of gloves, as well as the incorrect deployment of staff that are technically qualified and are deployed in the correct job (GRN MOHSS, December, 2008).

The following were moderately done: the training needs of health workers, including nurses, were moderately identified and diagnosed; planning of services according to the health information available at the health facility regarding morbidity and mortality were moderately planned for; training sessions for staff on relevant issues were moderately planned for; moderate care was exercised to ensure that the resources provided for nursing projects were utilised for the correct purpose; the effectiveness of health education programmes was moderately evaluated; findings were communicated in a moderately efficient way to stakeholders, both in writing and orally; moderate care was exercised to ensure that patients' health profiles were kept up to date at the health facilities; while all the training sessions conducted for both the community and staff members were documented moderately.

Some of the registered nurses indicated that this task of planning training sessions for staff was not applicable to their work situation. If training needs are identified, then the training sessions for the health workers could be conducted in such a way that the needs identified may be met. As with planning sessions for the community, it is equally important to plan training sessions for the staff, while the proper planning of a training session will ensure that the implementation of the session is both well-coordinated and goal oriented (Booyens, 1999). As in previous studies, the results of this study demonstrate that registered nurses'commitment to health education and health education programme approaches needs to be strengthened (Iiyambo, 2005; Neshuku, 2005).

The following functions required urgent dire action: programmes to manage illnesses were poorly planned; the budget was inadequately planned; there were insufficient contributions on the part of the registered nurses to the planning of proposals for a project; and registered nurses did not adequately adhere to budgetary requirements. Even if registered nurses are unaware of what has been budgeted for, it is essential that they see to it that the resources provided for the various projects in their units/facilities are utilised for the correct purpose. In addition, the health service must be protected from the misuse of valuable resources that are meant to serve the community, thus ensuring sustained services. It is recommended that this practice of ensuring that resources are used for the correct purpose should be encouraged in all practice settings, including those of nursing (Booyens, 1999; Jooste, 2010). The training of health workers, including fellow nurses, by registered nurses was inadequate, while the functions of the research role were not adequately carried out by the registered nurses.

\subsection{Summary of the findings on the independent varia- bles and the way these variables are related to the steps of the nursing process}

These results demonstrate that the area of work/health facility type and length of service at a health facility were perceived as relating to certain differences that were observed as far as the application of the nursing process in PHC competencies in practice was concerned. The following results were found: no significant differences were found in terms of assessment while, in terms of diagnosis, the duration of service at a health facility was related to a higher level of fulfilment of the role functions related to diagnosis. Registered nurses who had worked for four to ten years at a health facility were rated as doing well, followed by those who had worked at a health facility for more than ten years, while those who worked for three years or less at a health facility performed the lowest. However, the difference between group 2 (worked at a health facility for 4-10 years) and group 3 (worked at a health facility for more than 10 years) was not statistically significant. Nevertheless, this observation was made in terms of the group of registered nurses only and not the supervisors. As regards planning, the registered nurses and supervisors whose area of work was the health centre were more inclined to perceive that the fulfilment of their planning role functions was lower than those respondents whose working areas were not the health centre. The $\mathrm{p}$ value $=0.047$ for planning of PHC services by registered nurses whose area of work is health centre as opposed to those who work not in health centre.

In terms of implementation, two statistically significant differences were found, namely, with regard to gender and to area of work. Firstly, men were associated with better performance than women, $\mathrm{p}$-value $=0.018$, while the second statistically significant difference applied pertained to working in an outreach area and implementing the nursing process. It was found that those nurses who work in outreach areas were associated with better performances as regards the implementation of role functions of the nursing process $(\mathrm{p}$-value $=0.012$. The observation regarding gender applied to both groups, namely, the registered nurses and the supervisors, while the observation pertaining to area of work applied to the group of registered nurses only. Finally, no significant differences were observed in terms of either evaluation or documentation/recordkeeping. 


\subsection{Constraints facing registered nurses in local-level primary health care facilities as regards the execution of their role and functions}

The following constraints were suggested: Shortage of registered nurses; Registered nurses not involved in budget ; Registered nurses not briefed about the way in which budget allocation was adhered to; Registered nurses not provided with the necessary transport needed to carry out their functions ; Registered nurses are not exposed to certain activities for lengthy periods of time, for example outreach; Heavy workload, including large numbers of patients/clients to manage; Registered nurses do not have enough time to visit communities as a result of the heavy workload at the clinics and health centres. This workload makes life extremely difficult for the nurses.

These constraints were also identified by Neshuku (2005) and Iiyambo (2005). In the study of one district conducted by Neshuku (2005), regarding support for nursing staff in PHC, lack of transport was also one of the constraints identified. However, Neshuku also identified other managerial constraints, such as inadequate telephone communication and working space, as chal- lenges that were contributing to the difficulties faced by registered nurses. The findings of this study, when compared to those of Neshuku (2005), may have implications for a possible improvement in the management of PHC services in Namibia, or alternatively could mean that the challenges faced by registered nurses in local-level PHC facilities differ from those faced at the hospital level of PHC delivery.

4.6. Levels at which various primary health care roles and functions are fulfilled according to registered nurses and supervisors, and the challenges identified

4.6.1. Levels at which various primary health care roles and functions are fulfilled according to registered nurses and supervisors

Of the 67 PHC nursing role functions across the different phases of the nursing process, $20(30 \%)$ were categorised as well done, $30(45 \%)$ were categorised as moderately well done and $17(25 \%)$ were categorised as requiring urgent action

\section{Levels at which PHC role functions are fulfilled}

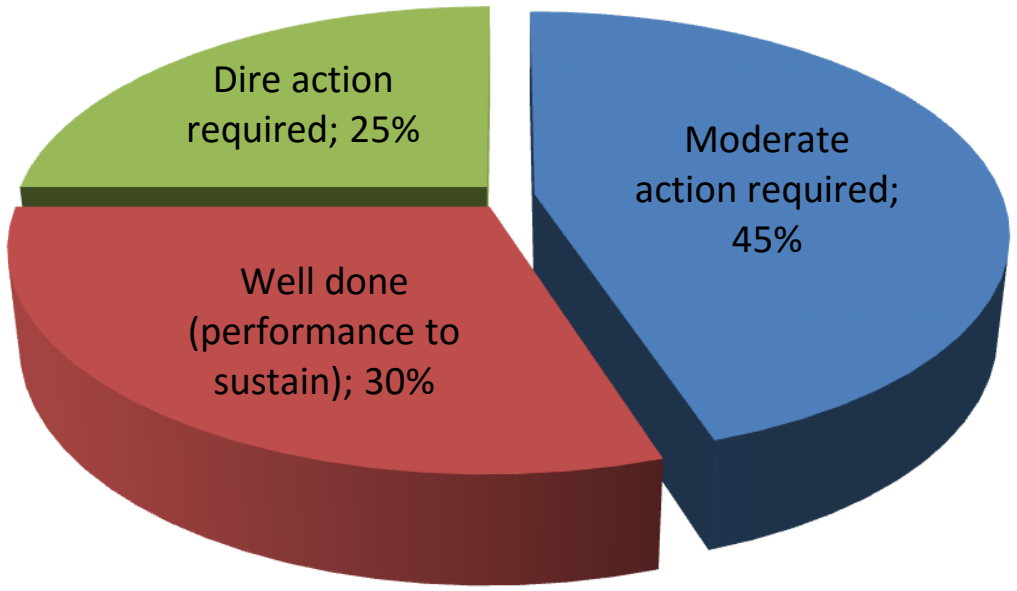

Fig. 3: Levels at which Various PHC Role Functions are Fulfilled by Registered Nurses in Local-Level PHC Facilities in Namibia.

These findings are graphically depicted in figure 3 . The ratings by the registered nurses and supervisors did not show a statistically significant difference, except as regards three role functions, namely, planning of programmes to manage illness, planning of training sessions for the community and training of health workers and community members.

In the case of the planning of programmes to manage illness, the data indicated that the registered nurses rated themselves higher as compared to their supervisors, who indicated that they felt that the planning of programmes did not merit a rating of

Average and higher. However, as regards the planning of training sessions for the community, the registered nurses rated their performance lower than did their supervisors, whose rating in this regard suggested they were quite happy with the way in which the registered nurses had been fulfilling this role function. Lastly, the training of health workers and community members was also rated more highly by the

Supervisors as compared to the registered nurses.

\subsubsection{Challenges identified}

The challenges identified fall into the following groups of PHC elements: water and sanitation and other environmental health issues (environmental hygiene); nutrition and food supply; health education and communication; community diagnosis and care; management and support or administrative function including research.

In a similar study conducted in 2005 on support in the form of resources made available by the MOHSS to PHC workers in the Onandjokwe District in the North West Heath Region, Namibia, it was found that a lack of resources hampered the fulfilment of certain of the PHC activities by registered nurses. As regards the management component of PHC, Neshuku also uncovered further managerial issues, including a lack of telephone communication and work space. These managerial issues were not picked up in this study (Neshuku, 2005).

Another study conducted by liyambo in 2005 , which focused on investigating information needs and accessibility of information of health workers in rural health centres, Iiyambo found that health care workers at this level realised what they needed to learn, but there was a need for information to be prepared in writing so as to enable health workers to be able to read the information for themselves (Iiyambo, 2005).

When the challenges identified were considered in relation to the steps of the nursing process, the areas of concern were found to be in assessment and planning. This finding, in turn, may imply that the diagnosis, implementation and evaluation may also be deficient in some areas because assessment and diagnosis guides all the functions which are implemented in order to solve the problems identified in PHC nursing. 
A detailed discussion on the challenges will be presented in a separate paper.

\section{Conclusions}

The results of this study show that registered nurses in local-level, PHC practice in Namibia fulfil most of the roles and functions expected of them. However, they do face some challenges which make it difficult for them to execute some of their roles and functions in this regard. This situation was evident in the views of both the registered nurses and their immediate supervisors and in the ratings they accorded to the various items in the questionnaires. The challenges were categorised according to the five elements of PHC and management, namely, water and sanitation and related environmental health issues; nutrition and food supply; health education and communication; community diagnosis and care; and management support or administration, including research. As regard the way in which supervisors view the use of the nursing process by the registered nurses, the results revealed that the supervisors of the registered nurses all had the same view as registered nurses regarding the fulfilment of the functions of PHC delivery.

\section{Recommendations}

It is, thus, essential that strategies to address the challenges identified be developed. A conceptual framework was devised as a basis for developing the strategies that will support registered nurses in their utilisation of the nursing process to improve the fulfilment of their PHC functions.

\section{Acknowledgements}

The researchers would like to express their appreciations to the following institutions and indiviaduals: University of Namibia for the financial and technical support; The Minstry of Health and Social Services (MOHSS) in Namibia for granting permission for this study to be carried out as well as for technical support; All the registered nurses who work in the local Primary Health Care facilities in the thirteen regions for the information they provided which helped to make this study happen

\section{References}

[1] Booyens, S. W. 1999. Dimensions of nursing management (2nd Ed.). Cape Town: Juta.

[2] De Vos, A. S., Strydom, H., Fouche, C. B., \& Delport, C. S. L. (2011).Research at grass roots: For the social sciences and human service professions (4th ed.). Pretoria, South Africa: Van Schaik.

[3] Ervin, N. E. (2002). Advanced community health nursing prac tice. New Jersey, USA: Prentice Hall.

[4] Government of the Republic of Namibia (GRN).Ministry of Health and Social Services (MOHSS) (1992).The Official National Primary Health Care/Community Based Health Care Guidelines. Windhoek Namibia: Ministry of Health and Social Services.

[5] Government of the Republic of Namibia (GRN). (2006). Progress report on the third medium term plan on HIV/AIDS. (April 2004March 2006).Windhoek, Namibia: Ministry of Health and Social Services, Directorate for Special Programmes, Division for Expanded National HIV/AIDS Coordination.

[6] Government of the Republic of Namibia (GRN) Ministry of Health and Social Services (MOHSS). (January 1995). The Integrated Health Care Delivery: The challenges of implementation. A situation analysis and practical implementation guide. Windhoek $\mathrm{Na}-$ mibia: Ministry of Health and Social Services.

[7] Government of the Republic of Namibia (GRN) Ministry of Health and Social Services (MOHSS). (24 March 2006). National Guidelines for the Management of Tuberculosis ( $2^{\text {nd }} \mathrm{ed}$.). Windhoek: Ministry of Health and Social Services.

[8] Government of the Republic of Namibia (GRN) Ministry of Health and Social Services (MOHSS). (December 2008). Namibian Essen- tial Medicine List (NEMLIST) $\left(4^{\text {th }}\right.$ ed.). Windhoek Namibia: Ministry of Health and Social Services.

[9] Government of the Republic of Namibia (GRN). Ministry of Health and Social Services (MOHSS) [Namibia]. 2006. Namibia Demographic and Health Survey. Windhoek, Namibia:(MOHSS)

[10] Heneman III, H. G., \& Judge, T. A. (2009). Staffing organizations (6th Ed.). Boston, MA: McGraw-Hill, Irwin.

[11] lipinge, S. N. (2000). Evaluation of the PHC/CGHC capacity building programme of the Ministry of Health and Social Services since 1992-1998. Windhoek, Namibia: University of Namibia.

[12] Iiyambo, L. (2005). Investigation information needs and accessibility of information of health workers in rural health center: A case study of Musty and Oshana regions. A project submitted in partial fulfilment for Bachelor of Arts Degree in Library Science and record management. Department of Information and Communication Studies, University of Namibia, University of Namibia Windhoek.

[13] Jooste, K. (2009). Supervision in nursing practice:Professional nurses series. Pretoria, South Africa: Van Schaik.

[14] Jooste, K. (2010). The principles and practice of nursing and health care:Ethos and professional practice, management, staff development and research. Pretoria, South Africa: Van Schaik.

[15] Kortenbout, W., Mtshali, N., Van Dyk, A. C., Van Wyk, N. C., Basson, P. M., Leech, R., \& Mchunu, G. (2009). Communicable diseases in Southern Africa. Cape Town, South Africa: Pearson Education South Africa.

[16] Levine, D. M., \& Stephan, D. F. (2010). Even you can learn statistics. A guide for everyone who has ever been afraid of statistics (2nd Ed.). New York, USA: Pearson Education.

[17] Lippincott Williams \& Wilkins (2006). Manual of nursing practice (8th Ed.). New York: Lippincott William \& Wilkins Publishers.

[18] Monekosso, G. L. (1994). District health management planning: Implementing and monitoring a minimum health for all package.Geneva: World Health Organization, Regional Office for Africa.

[19] Moseley, M. J. (2003). Rural development: Principles and practice. London: Sage.

[20] Neshuku, H. (2005). Support in the form of resources from MOHSS available to primary health care workers in Onandjokwe District in the North West Health Region, Namibia.Submitted in accordance with the requirements for the degree of Masters in Nursing Science at the University of Namibia.Department of Nursing Science. October 2005. Windhoek: University of Namibia.

[21] Nursing Professions Act 8 of 2004.Government Gazette of the Republic of Namibia. 3249. Namibia. Windhoek: Government printer

[22] Ott, R., \& Longnecker, M. L. (2010). An introduction to statistical methods and data analysis. (6th Ed.). New York: Books/Cole Cengage Learning.

[23] Searle, C. (1987). Professional practice:A South African nursing perspective. Durban: Butterworths.

[24] Searle, C., Human, S., \& Mogotlane, S. M. (2009). Professional practice: A southern African nursing perspective (5th ed.). Johannesburg, South Africa: Heinemann.

[25] Shikongo, K. K. I. (2008). Strategies to facilitate application of sociology of development to nursing practice. Doctoral thesis submitted in partial fulfilment of the requirement for the degree of doctor of nursing science in the Faculty of Medical and Health Sciences at the University of Namibia.

[26] Stanhope, M., \& Lancaster, J. (2008). Public health nursing: Population-centered health care in the community (7th ed.). Canada: Mosby, Elsevier.

[27] Stanhope, M., \& Lancaster, J. (2000).Community \& public health nursing (5th ed.). New York: Mosby.

[28] Stanhope, M., \& Lancaster, J. (2006). Foundations of nursing in the community: Community-oriented practice (2nd ed.). China: MosbyElsevier.

[29] Stanhope, M., \& Lancaster, J. (2010). Foundations of Nursing in the

[30] Community-Community oriented Practice. ( $3^{\text {rd }}$ ed.). St. Louis, MO: Mosby.

[31] University of Namibia.Faculty of Medical and Health Science. (1995). Diploma in Comprehensive Nursing and Midwifery Science (Updated curriculum). Windhoek: University of Namibia.

[32] Van Der Vyver, M. (2007).Guidelines to implement an educational programme to internalise and operationalize the nursing process in the genecology wards of the training hospitals of Namibia. Doctoral thesis submitted in partial fulfilment of the requirement for the degree of doctor of nursing science in the Faculty of Medical and Health Sciences at the University of Namibia. 
[33] Viljoen, M. J., \& Sibiya, N. (2009).History taking and physical examination (2nd ed.). Cape Town, South Africa: Pearson Education South Africa.

[34] Walliman, N. (2006). Social research methods. London: Sage. http://dx.doi.org/10.4135/9781849209939.

[35] Wilkinson, C. (2007). Professional perspectives in health care. China: Palgrave Macmillan.

[36] World Health Organization (WHO). (2009). WHO: Primary health care. Accessed from http://www.who.int/topics/primary health care/en/.on the $6 / 6 / 2009$. 